\title{
The emergence of an education policy dispositif in South Africa: An analysis of educational discourses associated with the fourth industrial revolution
}

\author{
Aslam Fataar
}

Department of Education Policy Studies and currently attached to the Transformation Office, Stellenbosch University, Stellenbosch, South Africa

afataar@sun.ac.za

https://orcid.org/0000-0002-6880-9223

(Received: 27 February 2020; accepted: 14 September 2020)

\section{Abstract}

The notion of the fourth industrial revolution (4IR) has recently entered the public and policy domain in South Africa. It has rapidly found resonance in policy discourse and the popular media. It has also entered the language of educational policy and institutions. The impact of 4IR on educational thinking and practice has hitherto not featured in academic discussion on education in South Africa except for a keynote plenary session at the annual conference of the South African Education Research Association (SAERA) in Durban (October 2019). The South African Education Deans Forum recently published a call for the submission of chapters for a book on teacher education, 4IR, and decolonisation.

In this article, I develop an address that I delivered at the SAERA 2019 conference as part of the plenary panel. The article consists of four sections. The first offers a consideration of the entry of 4IR discourse into the educational imaginary. I suggest in this section that 4IR discourse has installed a socio-technical imaginary in South Africa's unequal educational dispensation. The second section concentrates on the construction of educational governance. Based on research on 4IR-related policy making, I discuss the policy directions taken by the Department of Higher Education and Training and the Department of Basic Education in giving effect to ways of engaging with 4IR in each of their domains. The third section features a discussion of the impact of technological disruption on society, the economy and education. The final section presents a discussion of the emerging educational architectures in the 4IR and a critical consideration of the curriculum and pedagogical dimensions of 4IR, which, I argue, are informed by an orientation that prioritises the acquisition of generic skills. Sidelining knowledge and concepts as central to the structuring of the curriculum, a generic skills approach succumbs to what might be called a knowledge blindness that holds pernicious consequences for epistemic access in South Africa.

Keywords: fourth industrial revolution, education in South Africa, policy dispositif, educational governance, genericism 


\section{The discourse of the fourth industrial revolution's entry into the education imaginary}

The notion of the fourth industrial revolution (4IR) has entered our public dialogue over the last five years. It is said to have become then Vice-President Cyril Ramaphosa's political signature in 2016 upon his return from the World Economic Forum (WEF) meeting in Davos. The concept of the 4IR was incubated by the WEF President, Klaus Schwab, through his now renowned 4IR formulations explained in his text, The Fourth Industrial Revolution: What it means and how to respond (2015). Schwab explains in this text that

[w] e stand on the brink of a technological revolution that will fundamentally alter the way we live, work, and relate to one another. In its scale, scope, and complexity, the transformation will be unlike anything humankind has experienced before. We do not yet know just how it will unfold, but one thing is clear: the response to it must be integrated and comprehensive, involving all stakeholders of the global polity, from the public and private sectors to academia and civil society. (p. 1)

Ramaphosa's subsequent pronouncements reflect the WEF's language, especially since becoming the country's President in 2018. Upon his assumption of the chairpersonship of the African Union in February 2020, he called for the establishment of an Africa Artificial Intelligence Forum and made a rousing call for advancing 4IR on the continent:

... the 4IR presents our continent with great opportunities. The uptake of digital technologies will lead to improved competitiveness and provides fresh opportunities for inclusive growth. Millions of our continent's young citizens are digital natives and we must drive a skills revolution to enable Africa to take a quantum leap into the economy of the future. (Ramaphosa, 2020, n.p.)

This followed on from his establishment of a Presidential Commission on 4IR in April 2019 with the mandate to advise the government on 4IR policies, strategies, and multi-sectoral initiatives. The government's ambition is to position the country as a globally competitive player in 4IR. The Commission advised the President in a preliminary diagnostic report presented in November 2019 on strategies to harness the potential of technology as an enabler for growing the economy and creating much-needed jobs.

The discourses associated with 4IR are a good example of how we use language to construct the way in which we come to understand our social world. These discourses produce certain types of understanding of existing social and economic arrangements with consequences for preferred political prognoses and policy responses. Bessant (2018) alerts us to the use of metaphors and symbolism in such constructions, which, in the case of 4IR, describe developments in the economy, the impact of technological disruption, and its impact on unemployment. 
Such constructions have implications for the way in which a particular conjuncture is understood. In the light of this, 4IR in South Africa is hitched onto the policy path associated with the country's National Development Plan (NDP), specifically its skills-development agenda for dealing with youth unemployment. This, in turn, has knock-on implications for education and training, which I discuss below. 4IR discourse has had a decisive impact on the educational thinking of government, educational think tanks, and universities.

Bessant (2018) explains that a consequence of such constructions is the circulation in the public domain of particular framings of societal and educational problems as well as plausible assumptions about public policy problems and their solutions. She suggests that it is helpful to pay attention to the role that metaphors and symbolism play in shaping consciousness. A powerful example of such symbolism is the recent role of Pepper the Robot in announcing the 2019 National Senior Certificate matric results. I contend that the use of the robot signified the ascendance of 4IR discourse in the educational arena. Presented as an inevitable hallmark of 4IR in education, the Department of Basic Education (DBE) chose to signpost the core idea that robots will be used increasingly in routine work, with job losses and the changing nature of work as consequences.

The use of the robot lodged the idea that education and skills acquisition would have to respond decisively to the impact of technology on economic change and a rapidly changing labour market. The Minister of Basic Education (DBE), Angie Motshekga, underscored the inevitability of 4IR in a speech in January 2020 by announcing that "as you know, the fourth industrial revolution isn't a rumour but it's real." Blade Nzimande, the Minister of Higher Education and Training and Science and Technology presented a similar view. He suggested at the launch of Stellenbosch University's Centre for Data Science and Computational Thinking (July 2019) that the imperative for new skills places unprecedented demands on the government, business, civil society, and universities to cooperate in their use of technologies to advance the country's development. These governmental positions, from the President and key Ministers, posit a particular perspective on development as inevitable and should be taken seriously by education policymakers, institutions, and practitioners. It positions a particular kind of education logic in the social imagination—what Avis (2018) has called a "socio-technical imaginary" (p. 338). Avis explained that such an imaginary is based on rhetorical constructions of the 4IR which are located in understandings of the economy that are rooted in neoliberalism.

Avis (2018) claimed that 4IR is an ideological construct with specific material interests and that it has implications for education and training. For Avis, a 4IR socio-technical imaginary is based on recurrent themes such as artificial intelligence (AI), robotisation, digitisation, and smart machines. As imagery, the 4IR is saturated with popular culture and media tropes that are founded on the "transformative power of technology" (p. 341). 4IR is presented as holding the promise of addressing and resolving longstanding developmental challenges associated with health, welfare, and climate change. However, as Bessant (2018) and Avis suggest, what 4IR discourse hides from view is the relationship between technology and 
society, i.e. technology as embedded in social relations. Avis has reminded us that we cannot think of 4IR and disruptive technology outside of pre-existing social relations.

4IR discourse continues along the path of eliding the complex history of educational inequality in this country and the African context. It continues along a trajectory of framing educational development in the neoliberal terms that were ushered in by World Bankmandated structural adjustments in the mid-1980s on the African continent. Since the 1990s, South Africa has embarked along a path of fiscal austerity and quasi-market-related educational reforms in educational access, qualifications, and curricula. Allais et al. (2019) argued that the country has witnessed the reinforcement of inequality in the post-apartheid period. Their analysis is worth noting. They argue that the primary cause of educational failure is not the position advanced in the literature on educational effectiveness that highlights in-school factors such as weak institutional functionality, poor teachers' content knowledge, and reduced instruction time. Instead, according to them, the most important constraint and causal condition is the "socio-economic conditions that structure learners' lives in South Africa today ... [which] reproduce social and economic relations in ways that make it unlikely that we can improve equality of learning" (p. 106). In other words, educational outcomes can be improved only if widespread poverty is addressed and the social conditions of the majority improved. Such a position does not ignore the need for systemwide attention to in-school factors. In this view, poverty-stricken social conditions are regarded, correctly, as the primary cause of educational inequality.

The socio-technical imaginary that 4IR discourse installs is oblivious to the dynamics of educational inequality. Instead, 4IR is based on the view that closer attention should be paid to the vocationalisation of education and training. Skills acquisition is posited as key to educational reform in anticipation of producing workers who are able to work in a changing labour market. The notion of digital skills has quickly become a core framer of policy for the post-school sector. Thus, in public policy, amplified by popular media pronouncements, the emerging 4IR imaginary fails to account for the existing educational inequality in broader society. Instead, 4IR circulates the view that vocational and digital skills acquisition are the panacea for addressing such inequality. However, as Allais et al. (2017) argue, "even if the knowledge and skills of the workforce and potential workforce were radically improved, there is no evidence that this additional supply of skilled workers would create its own demand for labour, and therefore improve income inequality" (p. 106). The key point here is that the 4IR's focus on skills is presented as standing apart from the deeper educational inequality of which it is a part, and this in turn, has the effect of further deflecting the focus from the depth and complexity of such inequality.

The 4IR emphasis on a focus on skills is not unexpected. It comes on the back of concerted governmental attempts to improve the post-school sector during the last ten years. Hitched to the objectives of the NDP, the White paper for Post-School Education and Training (Department of Higher Education and Training, 2013) made an attempt to place transformation of technical and vocational education training at the centre of education development. Likewise, the Digital Skills Strategy published by the Department of 
Telecommunications \& Postal Services (DTPS, 2017), a key government 4IR policy player, explicitly links 4IR to its digital skills-development strategy. The strategy suggests that "[d]igital skills are one of the key skill sets required for the creation of new kinds of 21 stcentury jobs. Originality, agility, critical thinking and problem-solving are important 21 stcentury skills that must be interwoven with digital skills" (p. 6).

The emphasis on skills has emerged in the education policy domain on the basis of a human capital theory (HCT) view of education. HCT sees "people and their skills and knowledge as 'natural' or 'real' resources ... which education or learning enhances, thereby increasing our economic value" (Bessant et al. 2017, p. 90). This perspective posits that enhanced education and skills increase people's employability. HCT holds that education increases people's productivity by supplying them with knowledge and problem-solving skills, which would enhance their capacity to work in technologically changing workplaces. Governments have found such a perspective compelling in the light of their faltering national economies and rising unemployment. Vocational skills acquisition has become a core feature of South Africa's educational reform during the last twenty years. The increasing focus on skills was presented as part of broader neoliberal solutions based on market-based educational reforms. These reforms have hitherto not addressed the systemic educational inequality in South Africa. Describing the weakness of TVET structures and policy in South Africa, Allais et al. (2017) argue that "[skills-]development strategies . . have been more about posturing . . . than actually planning the development of the skills of the nation" (p. 13). It is therefore likely that the educational policy discourse associated with the 4IR, especially its focus on skills and the overhaul of the vocational education sector, would struggle to produce the type of medium- to high-level creative skills that the 4IR-impacted labour market would require. This would be difficult to achieve in the absence of an overall qualitatively enhanced educational system. A properly functioning post-school sector is unlikely to emerge. The rapid incursion of 4IR-related educational discourses has contributed to the further erosion of a focus on systemwide educational inequality. Instead, what we have seen is the introduction of a powerful 4IR social-technical imaginary that is informing the policy making and governance process in education.

The definition of discourse that I use in this article draws on the work of Ball (1993), who argued that discourse produces the frameworks, meaning-making, and sense of obviousness with which policy is thought, and talked, and written about. Policy "set within these frames works to constrain but never determine all of the possibilities for action" (p. 11). In similar vein, 4IR educational discourse is made up of position papers, research, and policy-related grey literature advanced by educational and non-educational actors operating in the governmental sphere. During the last five years, 4IR-related educational discourse has come to speak us. I argue that we need to appreciate the ways in which 4IR educational discourse has assembled propositions, words, symbols, and metaphors to construct certain ways of understanding the world and disqualified other perspectives, as Ball has reminded us. In this way, certain possibilities for educational thought and action have become acceptable and normalised. In the next section of the article, I present an account of the nature of educational governance in response to the 4IR imperative. 


\section{Discursive construction of 4IR educational governance}

This section is based on my application of critical policy theory lenses to guide my sensemaking of governmental policy discourse on 4IR. My research for this section has involved what is called policy analysis at an awkward scale, which is a type of distended, fast-moving case study (see Ball 2016). I offer what Ball (2016) thinks of as a networked ethnography of policy development that emphasises policy mobilities across global/local scales, network dynamics, and the local assemblages of policy meanings. This section is based on my interviews with government officials, as well as on policy documents, grey literature, and media articles, and my participation in 4IR workshops, conferences, and discussion fora. ${ }^{1} \mathrm{I}$ tried to understand how 4IR as policy discourse has come to be constituted, and how 4IR has become the prevailing educational discourse that now speaks us.

The story is picked up from when 4IR was conceptualised by Klaus Schwab of the WEF from 2014. Schwab and the WEF's 4IR formulations feature strongly in local 4IR formulations. Governmental processes are coordinated by the Minister of the newly named, in June 2019, Department of Communications and Digital Technologies. Minister Stella Ndabeni-Abrahams, an authoritative governmental political actor, leads on 4IR-related activity in the governmental domain. President Ramaphosa constituted a 4IR Presidential Commission with the University of Johannesburg's Vice-Chancellor, Prof. Tshilidzi Marwala, as its vice-chair and Ramaphosa himself as the nominal chair of the Commission. Marwala is a key 4IR policy player. He is regarded as one of the country's most important 4IR influencers with substantial scholarly output in the fields of AI, engineering, and innovation. He publishes opinion pieces on 4IR in popular media sites such as the Daily Maverick, an online news platform.

The 4IR Commission is meant to develop policies, strategies, and action plans. Its 30 members are drawn from a broad range of social sectors dominated by technology, science, innovation, engineering, entrepreneurship, software development, skills, data science, telecoms, and industrial development. The Commission's work is divided into six workstreams: infrastructure and resources; research, technology and innovation; economic and social impact; industrialisation and commercialisation; and policy and legislation. Importantly, the sixth is a workstream on human capital and the future of work chaired by Beth Arendse from the creative industry. This indicates that the educational prerogative of the Presidential Commission is framed around creativity, skills, and employability.

The WEF's Future of Jobs document (2016) features strongly in the make-up of the framing discourses around 4IR, emphasising the need to adapt the economy to include enhanced computational thinking, transdisciplinarity, virtual collaboration, technological literacy, and entrepreneurial skills. Echoing WEF framings, the South African government's policy

As mentioned below, I was a member of the Ministerial Task Team of the Department of Higher Education and Training from November 2019 that produced a report on higher education and the fourth industrial revolution. The report was formally handed over by the Task Team to Minister Blade Nzimande in September 2020. I did not interview any of the task team members for this article. This article was written relatively parallel to, and separate from, the deliberations of the task team. 
documents emphasise 4IR's impact on the world of work, work disruption, and job losses. The documents also emphasise skills planning, right-skilling the workforce, and future competences.

Recent government documents are replete with references to scenario planning, governance, statistical projections of jobs, and economic growth. Examples of these documents are the National Treasury's journal called the Service Delivery Review (National Treasury, 2018) and the National Plan for Post-School Education and Training 2019-2030 (DHET, 2019) published by the Department of Higher Education and Training. Global consultancy firms such as Accenture, Learning for Improvement, and McKinsey actively feature in various discussions on the 4IR conference circuit. Local technology and engineering firms have been occupying various discursive and performance spaces in which 4IR is advocated. References to multilateral and multi-country initiatives in info-tech and economic development are also prevalent in 4IR-related conferences and symposia. We have witnessed the mushrooming of a number of advocacy spaces at various urban universities and in business-hosted discussions.

4IR discourse is currently being sold by an intersection of networks active in universities, as well as in the commercial, info-tech, and innovation sectors of our society. The Centre for 4IR South Africa, for example, was set up by a loosely coupled business-led organisation that facilitates network functioning in and around government. The high-tech community, creative industries, and business innovators are active on the 4IR circuit. University executives are playing a crucial role in generating consent. Vice-Chancellors at the Universities of Johannesburg, Pretoria and the Witwatersrand are, for example, punting 4IR as a way of seeking academic niche advantage. We have seen 4IR-related conferences hosted by university outfits. South Africa has seen multiple conferences, workshops, and symposia during the last 24 months, all mainly circulating WEF-type 4IR discourses. Various actors or what Ball (2016, p. 553) calls "policy entrepreneurs", with reference to strategically positioned people who join up disparate 4IR-related activities, spaces, and initiatives, are central to circulating influential 4IR policy framings. It is interesting to note that little critical discussion has emerged that interrogates the 4IR phenomenon, indicating a sophisticated, yet to be understood, type of manufacturing of consent at play.

My interviews with members of government departments prominent in 4IR-related policy development indicate that the WEF discourse has become authoritative as a result of the networked interaction between government policy actors, the information technology-related business community, and key university-based players. In this light, the role of digitisation in fuelling technological development and innovation has become central to 4IR governmental discourse. Key government documents locate digital and technological skills as one of the main constitutive features of, and a response to, the 4IR discourse, in which education and schooling are positioned to play a central role (see DTPS, 2017; DHET, 2019).

It is apparent that what Peck and Theodore (2016) refer to as "fast policy making" (p. xvi) is visible in the assembling of the 4IR policy discourse, constructed as it were on the hoof, in motion, in talk spaces, and in the joining up of disparate activities. It is clear that the global to local flow of discourses end up in government via policy entrepreneurs who join up disparate 
governmental and non-governmental activities to produce the policy discourse. What is clear is that 4IR governmental discourses are constituted by a multiplicity of networked interests and actors across global and local scales which come to influence policy language and positions. The era of a unitary government making policy relatively autonomously in the service of the broad polity is long gone. Instead, 4IR policy discourse is produced by networked governance-type policymaking with spheres of influence from outside and inside government. Such policy discourse is driven by the commercial logics of niche-seeking activity, and also by universities seeking to position their research and teaching programme offerings in response to anticipated 4IR labour market needs.

Theoretically, following Bailey (2013), what has emerged is captured by the idea of a policy dispositif, which refers to a shifting material-discursive formation that shapes ideas of how to govern. Bailey has explained that the notion of dispositif refers to an amorphous policy formation comprised of a multiplicity of heterogeneous elements, including material objects, discourses, practices, and subjectivities. In the case of 4IR educational discourse such a policy formation is the outcome of strategic struggles inside and outside government over the meaning and governing of education. The 4IR dispositif enacts a mode of policy regulation with the capacity to produce, regulate, and govern educational practices and practitioners. In line with Avis (2018), cited earlier, it can be argued that the 4IR policy dispositif is a socio-technical formation of government, which informs government's conduct of conduct in the way it regulates its own behaviour to behave in a particular way, which, in turn, reflects dominant political rationalities.

The 4IR dispositif is, however, not a closed formation; it is a strategic battlefield, or struggle, over the governing of education (see Bailey, 2013). Key to policy dispositif generation, I argue, is understanding how the 4IR dispositif ends up in the educational sectors of government, i.e. in the DBE and the DHET. My interviewees in these two departments displayed what they called some "scepticism" at the "fad" and "hype" over 4IR. Statements by interviewees displayed hesitation about uncritical acceptance of the premises of 4IR in terms such as "We're an implementing agency", or questioning whether "We'll now ignore all the policy frameworks that we have recently developed." They worry over whether new priorities associated with 4IR would override older priorities. The interviewees in the two education departments linked 4IR to prior departmental policies on TVET, skills, qualifications, technology, the SETAs, open learning platforms, and computing skills.

Compared to the DBE, it seems that the DHET displayed what was thought of as a cautious micro dispositivity amidst complex Post School Education and Training arrangements. The DHET is developing a set of policy documents that prioritises digitisation and associated skills, which, importantly for them, connects with the Department's broader policy goals of addressing unequal access. Former Minister of Education, Naledi Pandor, appointed an eightperson DHET ministerial task team in May 2019 to deliver a set of policy and strategy proposals in early 2020. It was made up of academics specialising in AI and digitisation, people from banking, trade and industry and economic transformation, and a journalist who focuses on youth and women's issues. A person from Harambee Youth Employment 
Accelerator, an outfit that provides employment pathways for youth, was also on the team, representing education and skills expertise on the task team. After questioning the absence of an education and curriculum person, I was appointed in November 2019 to the task team as someone with teacher education and curriculum-related expertise.

The digital skills agenda in the Department of Basic Education displays a firmer micro dispositivity. The DBE hitched the 4IR discourse strongly onto its prior commitment to expanding digitisation. The DBE produced a policy paper called Digital Skills Framework Grade $R$ to 9 (2019) with strong 4IR framing language. This framework document was written during a 4-day workshop by a 9-person team consisting of a DBE official in the Mathematics, Science, and Technology division, university lecturers in Information Technology (IT), a provincial IT coordinator and representatives from edu-tech nongovernmental organisations.

The framework document proposes a Digital Skills for All curriculum as a stand-alone subject to be introduced in the General Education and Training (GET) phase to prepare learners for enhanced living, further study, and employment opportunities in a digital world. The DBE document intends to provide learners with the foundation for future life, work, and careers in computational-based problem-solving fields in the 21 st century. Its curriculum development emphasis is on somewhat familiar conceptual competence categories based on skills and outcomes, with an emphasis on transfer approaches and learning materials. More concretely, the DBE has developed curriculum statements for the subjects Robotics and Coding, for each subject per grade. The DBE intended to roll out the teaching of Coding for Grades 5 to 7 from 2020 in schools across five provinces. In contrast to the DHET, the DBE's firmer micro dispositivity has thus already led to concrete policy implementation aligned with the dominant digital skills-informed vision of 4IR inside government.

In this section, I discussed the discursive construction of 4IR educational governance in South Africa in recent times. I provided a consideration of the networked policy influences at play inside and outside of government in constituting 4IR discourse. I suggested that 4IR's discursive construction is an example of networked governance processes that operate from the international to the local government sphere and that this involved a range of policy actors, institutions, and business-related outfits. The result is the formation of an overall 4IR governance dispositif that has entered the micro-governance terrains of specific departments. I showed how 4IR discourse has been taken up in differentiated ways in the different education departments, depending on their internal policy and political priorities. I argued that 4IR as educational discourse has real effects in public life in respect of the way it has come to impact on the work of institutions. It has had an important formative impact on institutional research and innovation efforts, teaching programmes, and curriculum adaptation. Moving from the discursive to the concrete impact of 4IR, in the next section I present an account of the impact of 4IR on society and the economy, with implications for education in the context of rising unemployment caused by technological innovation. 


\section{Discourse as real: Implications of 4IR for society, the economy, and education}

Since 2015 the 4IR discourse has entered the unequal social and educational circumstances of South Africa. Initially, it lodged imperceptibly in public policy discourse. During the last two years 4IR discourse has had a formative (real) impact on educational governance via policy initiatives and institutional practices. In this section, I discuss some aspects of the impact of 4IR on society and the economy and its educational dimensions. I argue that the 4IR-related educational reforms are characterised by the rise of what Young and Muller (2010) label future 2 genericism. This refers to the clamour for a focus on generic skills to underpin a 4IRresponsive curriculum and pedagogic platform.

Emerging from around 2000, the distinctiveness of 4IR compared to earlier industrial revolutions, is the rapid increase in the operating speed that now characterises technologically connected developments. Schwab explained that 4IR "is evolving exponentially rather than along a linear path ... disrupting almost every industry in every country [and] herald[ing] the transformation of entire systems of production, management and governance" (2015, p. 1). Suggesting a way to understand the workings of the current age, Bessant (2018) argued that what we are living through can be regarded as the onset of a techno-axial age. She explained that "far-reaching and fundamental changes are now underway ... [and] we are witnessing the end of the order of life and ways of being human" (p. 14). The techno-axial age is based on a cognitive revolution "in the ways human life and activities like productive work, technical activity and play are organised, practised and reproduced" (p. 44). It involves rearranged interactions between humans and technology, thereby changing what it means to be human.

Bessant (2018) suggested that digital technologies are the "new interface between mind and world" restructuring the memory systems of the brain, memory and retrieval systems, and human consciousness (p. 44). These changes involve how we now enact human action at a distance and the ways in which we are severing longstanding links between human consciousness, labour, and action. These changes affect the basic patterns of the social relations that define our human experience and existence. The traditional nexus between work, labour, and income are being severed. This led Bessant to ask what the future of human work would be in the emerging economy, and importantly, how humans would secure their livelihoods. Changing labour markets and the nature of available work play an important role in understanding 4IR related educational processes.

Those who write on 4IR and education agree that central to 4IR is the existence of computing capacity that can store massive amounts of data, which, in turn, ignites deep machine learning as the central motor of systems development (see Gleeson, 2018; Penrose, 2018; Peters \& Jandric, 2019). The term cyber-physical systems (CPS) was coined to describe the "physical and engineered systems whose operations are monitored, coordinated, controlled and integrated by a computing core" (Rajkumaret al., 2010, p. 731). CPS presages the existence of a single global technical system that, according to Peters and Jandric (2019), interlocks all 
corners of the globe into a single planetary system. An integrated CPS means that technologically based disruption has become the order of the day. The disruptive effects on the economy and labour market have profound implications for the nature of jobs, unemployment, and the demands for new skills.

Understanding the nature of labour demand is essential for an accurate depiction of the capitalising logics of 4IR, its productive dynamics and the critical questions that this raises for education. Boateng (2008) described the capitalist mode of production that we are living in as a form of cognitive capitalism with reference to the centrality of forms of knowledge based on what he calls algorithmic reason that is fuelling the current political economy. Immaterial or cognitive labour, as opposed to material manual labour, is touted as central to the digital economy, which signals significant shifts in the economy involving technological disruption and unemployment. Job loss statistics in South Africa (see Statistics South Africa, 2019) show that it is in the repetitive white-collar sector, in finances, banking, law, and accounting that jobs have been shed over the last few years. Schwab explained that "in the future, talent, more than capital, will represent the critical factor of production. This will give rise to a job market increasingly segregated into 'low-skill/low-pay' and 'high-skill/high-pay' segments" (2015, p. 3). Sutherland (2020) argued that the automation of work and the loss of jobs are central concerns of 4IR. He quotes from the 2018 McKinsey Global Institute report that forecasts a rise in job demand for workers with advanced technological skills. This position is corroborated by Frey and Osborne whose future skills type analysis shows that new work will require a higher degree of cognitive ability, with a corresponding decline in demand for workers with low cognitive skills (2015, p. 89). This is a particularly difficult challenge in a country such as South Africa, which has a persistently low-level skills regime and a poorly functioning human resource development sector (see Allais 2013).

Based on the rise of blockchain, artificial intelligence, 3D printing, and the internet of things, job opportunities have emerged in the creative knowledge and data application industries. These industries require integrated multidisciplinary educational platforms based on new combinations of disciplines, parts of disciplines, programmes, and qualifications.

Computational thinking, data processing, and combinations of work-related knowledge offerings are presented as critical to such an educational platform. Following Peters and Jandric (2019), the critical question raised by 4IR turns on the role and function of education in confronting technological unemployment. These scholars pose this question dramatically to alert us to the ways in which the purposes of education are being re-arranged as a result of the broken covenant between education and jobs. In other words, they force us to think about the public purposes of education in the light of the collapse of a positive correlation between education and employment in the context of 4IR. This consideration must be processed in the South African context where responsiveness to the 4IR imperative has to take into account the prevailing inequality and the existing lack of functionality and quality across the education system. 


\section{IR education architectures and their curriculum modalities}

In this final section of the article I discuss some of the main 4IR-related educational reform initiatives that have emerged during recent times. I provide a critical reading of how these reforms have begun to impact on the education architectures of institutions. I also offer a consideration of what can be regarded as the primary curriculum and pedagogical dimensions of 4IR. I argue that the acquisition of creative skills as the foundation of a 4IR education system plays a formative role in defining the nature of the curriculum. Such a position is motivated by the need to have education respond to job losses and labour market demand. 4IR-based reforms place generic skills at the centre of educational development, which, I argue, holds potentially pernicious consequences, especially for developing countries such as South Africa.

4IR education advocate, Bryan Penrose (2018) offers a compelling account of the purposes of education in adjusting to 4IR. Focusing on an economic rationale for educational reform and the skills demands of the workplace, he has explained that on

strictly economic terms, students who are capable of creative insights, collaborating in diverse realms, and navigating through global cultural differences, will be at an advantage in a workplace ... [This makes it necessary to] develop more interactive forms of pedagogy at all levels and to embrace a curriculum that stresses perspectives from multidisciplinary and cultural perspectives over static swathes of disciplinary 'content.' (p. 225)

This position by Penrose gives pride of place to the acquisition of creative skills, interactive pedagogies, and multidisciplinary perspectives, which would replace a focus on the acquisition and transfer of disciplinary content. Gleeson elaborated on this perspective by explaining that "metacognition is important ... whatever combination [of multiple knowledge perspectives] you apply ... the bottom line is that creativity is key" (2018, p. 7).

Essential to such a curriculum perspective is responsiveness to the accelerating pace of technological change. What is required is a drastic reconsideration of the curriculum to enable students to comprehend the role and function of technologies, adapt to them and "be able to thoughtfully analyse and predict the evolution of networked systems of technology, the environment and socio-political systems" (Gleeson, 2018, p. 224). Emphasising the acquisition of generic skills, 4IR advocates (see Aoun, 2017; Gleeson, 2018) argue that more than any particular content area, a curriculum needs to help students develop the capacity for ethical reasoning, and for awareness of societal and human impacts. Students have to be able to comprehend the impact of 4IR technologies on people, the economy, and the environment, so that they are trained not only to increase our material prosperity but also to improve our social and cultural fabric. Penrose (2018) presented such a vision in rousing terms by suggesting that education has to adopt and scale-up "new 4IR forms of education rapidly to ensure the sustainability of our environment and economy" (p. 225). Such a view is 
corroborated by Gleeson (2018), who argued that education has a pivotal role to play in shaping the societal transitions necessary to adjust to the 4IR.

That such a utilitarian view has come to dominate significant aspects of our reform imaginary is the outcome of broader struggles over symbolic domination in society and education. The dominant curriculum and pedagogic modes that are adopted in education institutions are reflective of these broader struggles. The dominance of 4IR rationales and reform initiatives is facilitated by a range of systemic reforms aimed at adapting existing education architectures, which, according to Gleeson (2018), were designed to meet the needs of past industrial revolutions. These systems have to be reformed to meet the needs of the automation economy.

In relation to the higher and vocational education sector, a key systems recommendation of 4IR is the idea of what can be thought of as an open-loop education platform on which students are able to combine building their educational foundations and blending their skills acquisition over their early adult careers. Blending their on-campus learning with experiences in the workplace is central to such a platform. Students can enter and exit the workplace and various real-life situations and return to campus with experience of practice. Newer forms of assessment would be a requirement for open-loop education. In addition to connecting education to work, 4IR education emphasises the need for students to update their content and skills to match the rapid tempo of scientific and technological advances (Penrose, 2018). Lifelong learning is regarded as crucial for keeping employees' skills updated to meet the requirements of the labour market.

The use of technology is regarded as central to the 4IR education platform. ICTs are key in the delivery of courses. In addition to Massive Open Online Courses (MOOCs) and blended learning, a number of other ICT initiatives have emerged to deliver course learning. Some of the most prominent are the use of artificial intelligence (AI) in teaching, e-learning technologies for simulation and practical demonstration, on-line information education environments, flipped classrooms, and on-line tutoring.

Reform in the areas of science, technology, engineering, and mathematics (STEM) has received prominence. It is envisaged that the STEM curriculum be adapted to combine the primary sciences of biology, chemistry, and physics with emerging areas of genomics, data science, AI, robotics, and nanomaterials. New courses in life science, engineering, and chemistry would, for example, be designed in combination with applied fields related to the application of emerging technologies. Bioengineering and Green Chemistry are regarded as examples of degree programmes that are located at the interface of various combinations of disciplines and technological applications in order to target the development of innovative research, technologies and skills for resolving health challenges and confronting disease.

4IR advocates are calling for new frameworks to be developed to enable vocational education to respond to the volatility and complexity of work. The sector would have to shift from a preoccupation with routine skills to developing "habits of mind and capacity for creativity within workers at all levels" (Penrose, 2018, p. 202). The integration of 4IR technologies is 
regarded as important for developing creative skill sets among students. In response to the changing nature of work, which now requires shorter and more flexible work assignments, a range of shorter training courses should be made available to update workers' skills and reeducate them during times of unemployment. These courses would aim to keep workers integrated into the changing workplace.

An open-loop education is responsive to newer modes of learning to renew skills. It is based on what are described as stackable micro-credentials that students could acquire over the duration of their studies, which they would pursue while moving in and out of education and the workplace. A combination of asynchronous online learning, synchronous face-to-face learning environments involving more than one institution, and workplace learning would be key to 4IR education platforms. Key to the viability of such a platform is the accreditation of courses across different educational formats. The argument is that accreditation of hybrid programmes based on the use of different formats would be facilitated by a flexible qualifications framework able to accredit the accumulation of micro-credits across these different formats in an open system of learning. Increasingly, therefore, flexible modes of delivery and hybrid programmes delivered by a mix of institutional and workplace arrangements are becoming the hallmark of 4IR-related educational platforms.

This leads me to the kernel of my argument with respect to the triumph of a generic skills emphasis in 4IR curriculum and pedagogy. This emphasis is in reference to a curriculum orientation that favours the logic of the acquisition of generic 4IR-related creative skills as the overriding imperative. If the dominant purpose of education is presented as a response to technological unemployment by providing skills acquisition, then it stands to reason that a generic skills orientation is a logical curriculum and pedagogical response. Such a view has arisen, as argued earlier, on the basis of a human capital theory view of education that favours skills acquisition as the panacea for employability and economic development.

As I show below, a generic skills focus places the emphasis on learners' acquisition of 4IR skills, while backgrounding the knowledge to be taught and learnt. Such a view is borne out by the educational literature on 4IR. Genericism has been with us for more than 30 years. It has, however, accelerated rapidly during the last decade. Emphasis on generic skills has quickly become a core foundation of education policy, curriculum, and pedagogy. Two universities in different parts of the world, Northeastern University in Boston, USA, and Taylor's University in Malaysia, are examples of two institutions with an explicit 4IR institutional focus on generic skills acquisition. Joseph Aoun, the President of Northeastern University, explained "that to stay relevant in the new economic reality, higher education needs dramatic realignment” (2017, p. xii). The university's curriculum is explicitly organised to address the educational challenges associated with employment and skills in the 4IR. Its formal institutional curriculum is an example of an explicit generic skills orientation and pedagogical approach. The university has designed what it claims is a unique human education. Labelled Humanics, the curriculum is based on experiential and lifelong learning, use of digital technologies, and workplace learning. Aouan's (2017) book describes the university's explicit focus on the acquisition of three types of literacy and four types of skill. 
Technological, data, and human literacies are touted as the crucial new literacies that students have to acquire during their learning. And regarding higher-order generic skills and capacities, the acquisition of critical thinking, systems thinking, entrepreneurship, and cultural agility are privileged.

Similar to Northeastern University's generic skills focus, Taylor's University believes that in the face of much disruption in the Fourth Industrial Revolution, the rapid changes in the workplace demand that university graduates exhibit competencies beyond discipline-specific knowledge. The skills that are important are lifelong learning, critical thinking, social intelligence, problem solving, resilience, and adaptability. Taylor's University proceeded to organise its entire curriculum offering to "ensure learners know, develop and culminate these skills upon graduation" (Nair, 2020, p. 1). The university aims to produce competent graduates who "possess transferable or portable skills instead of only "informed graduates", (p. 2).

Northeastern University uses multiple tools to teach with the emphasis on literacies and skills, while avoiding an overemphasis on content. This involves thematic study across disciplines based on hands-on project-based learning and real-world connections. Emphasising the importance of active student learning, Taylor's University has developed what it calls a Teach Less Learn More pedagogical approach. This refers to an attempt to accord quality time in the classroom for interaction, opportunities for expression, and developing critical skills. Such an approach eschews a preponderance of "face to face teaching and rote learning, repetitive tests, and following prescribed answers and set formulae." The aim of this approach is to reduce the emphasis on "vast specific knowledge and repetitive tests" (p. 4) and have this replaced by students engaging in active and interactive learning.

Such a student-centred learning approach was described by Biesta (2006) as central to the socalled learnification of education that we have been experiencing since the 1990s.

Learnification refers to student-centred learning facilitated by digital and online formats as the dominant pedagogical mode. Biesta argued that such a view of learning sidelines teaching and teachers, is based on an input-output model, and shifts the pedagogical focus away from the complexity involved in knowledge and skills transfer and acquisition. As preferred pedagogical mode, learnification combines with a focus on generic skills acquisition as the defining features of what Young and Muller (2010) labelled a Future 2 curricular orientation. Such an orientation is based on what they call an over-socialised concept of knowledge, a steady weakening of knowledge boundaries, and the de-differentiation of knowledge and institutions. The key point for our discussion is that a Future 2 orientation places emphasis on generic outcomes rather than inputs. They explain that Future 2 emphasises learner-directed education, the introduction of digital technologies, and the deprofessionalisation of teaching. Consonant with 4IR curriculum formats, the Future 2 approach emphasises disciplinary integration, facilitative learning pedagogies and, importantly, the stipulation of generic skill outcomes. 
The two universities that I discuss above have an institutional focus on a generic skills-based 4IR curriculum. They are examples of an attempt by 4IR educational platforms to respond to the need to produce highly skilled cognitive labour to work in the 4IR economy. The focus on generic skills, however, fails to account for the necessity of centring knowledge and knowledge boundaries in the curriculum. In contrast, Young and Muller (2010) have explained the role of knowledge boundaries in the acquisition of knowledge and skills. They argued that there is an "intimate link between knowledge form and curriculum organisation" (p. 20). The sequencing, pacing, and hierarchical organisation of concepts in any curriculum are dependent on an acute understanding of the knowledge of old and new subjects, modules, or courses. This also applies to the newer multidisciplinary combinations propagated by courses and modules responsive to 4IR. The knowledge structure of curriculum combinations forms an important part of their conceptual scaffolding logic, without which conceptual learning cannot take place.

The focus of the 4IR curriculum is to emphasise generic skills and student learning, and its de-emphasis of disciplinary learning, concepts, and content knowledge means it falls into the trap of what Maton (2014) has called knowledge blindness. Such blindness is a reference to the absence of knowledge in the structuring of the curriculum. 4IR's Future 2 type genericism is characterised by skills-based priorities that neglect the acquisition of knowledge and concepts, with the result that the curriculum becomes "conceptually under-stipulated" (Young \& Muller, 2010, p. 22). The critique of Future 2 genericism lies in the inability of such a curriculum to provide students access to the conceptual knowledge upon which the acquisition of knowledge and skills depends. In an educationally unequal country like South Africa, which does not have a quality system of general education, the move to a curriculum that emphasises generic skills would mean that the majority of its students would not be in a position to obtain access to the curriculum knowledge that would enable them to establish sustainable livelihoods in a complex world and obtain the necessary cognitive skills for employability in the 4IR labour market.

\section{Conclusion}

In the first section of this article, I presented a discussion of how 4IR has come to settle on the educational discursive terrain and has established its prominence based on a human capital view of education. In the second section, I focused on the discursive construction of educational governance and its associated policy prescriptions in various parts of government. I argued that the emergence of a policy dispositif shaped the way 4IR became ensconced in educational governance, with implications for governmental policy. Moving beyond the discursive imprinting of 4IR and the framing of educational governance in the country, in the third and fourth sections I presented the argument that 4IR has had a formative societal, economic, and educational impact. It is, for example, impacting on government education policy and curriculum as well as on curriculum and pedagogical practices at institutions. 
The changing profile of the economy and the labour market is in large part the result of the impact of disruptive digital technologies. The rapid increases in job losses in the economy's repetitive work sectors, on the one hand, and the availability of jobs, especially in the creative sector, on the other, have impacted on the education sector's response to unemployment. Education in the context of 4IR has been adapting to the spectre of the rapid increase in unemployment. Education in the 4IR is being built on a range of systemic architectural reforms that are instantiating open-loop platforms for accumulating education credits over a flexible longer-term duration. In such a situation, students would be able to build up their education programmes in more than one institution, spend periods in workplace learning, and engage in a combination of synchronous and online asynchronous learning. These types of architectures are now rapidly emerging in educational institutions, changing the way education is accessed and experienced.

In the last section of the article, I presented the view that the 4IR favours a curriculum logic that is founded on the triumph of generic skills acquisition acquired via student-centred pedagogies. I suggested that such a view discounts the role of knowledge, concepts and teaching in the acquisition of bodies of knowledge and skills, and I suggested that such a view, therefore, represents an inadequate account of a curriculum for sustainable and productive living.

My normative engagement with the 4IR is based on the realities associated with its impact on society and education. I eschew a politics of refusal that fails to grapple with how education is currently being re-arranged by technological disruption. This article is based on a critical interrogative stance aimed at understanding the social, economic, and educational dimensions associated with 4IR. Such an attitude is informed by the need for research-based understanding of the impact of 4IR processes on educational functioning. We have to research the ways in which 4IR impacts on development in science, technology, and innovation. Research should also be pursued on the adoption of curricula and pedagogies across the wide range of education institutions. We should attempt to understand whether students are prevented from gaining equitable access to the knowledge and skills necessary for their epistemic becoming. The terms on which we should harness the positive dimensions of 4IR, or resist its worst consequences, especially in the context of educationally unequal countries, remain subject to ongoing debate, dialogue, and struggle.

\section{Acknowledgement}

I thank Prof Eugene Cloete, Vice-Rector: Research, Innovation and Postgraduate Studies, Stellenbosch University, for providing funding for the project on which this article is based.

\section{References}

Allais, S. (2013). Understanding the persistence of low levels of skills in South Africa. In J. Daniel, P. Naidoo, D. Pillay \& R. Southall, (Eds.), New South African review 3: The second phase - tragedy or farce? (pp. 201-220). Wits University Press. 
Allais, S., Cooper, A., \& Shalem, Y. (2019). Rupturing or reinforcing inequality? The role of education in South Africa today. Transformation, 101, 105-126.

Allais, S., Marock, C., \& Ngcwangu, S. (2017). Planning, plumbing or posturing? Explaining the weakness of human resource development structures and policies in South Africa. Journal of Education and Work, 30(1), 13-25.

Aoun, J. (2017). Robot-proof: Higher education in the age of artificial intelligence. MIT Press.

Avis, J. (2018). Socio-technical imaginary of the fourth industrial revolution and its implications for vocational education and training: A literature review. Journal of Vocational Education \& Training, 70(3), 337-363.

Bailey, P. (2013). The policy dispositive: Historical formation and method. Journal of Education Policy, 28(6), 807-827.

Ball, S. (1993). What is policy: Texts, trajectories and toolboxes. Discourse: Studies in the Cultural Politics of Education, 13(2), 10-17.

Ball, S. (2016). Following policy: Networks, network ethnography and education policy mobilities. Journal of Education Policy, 31(5), 549-566.

Bessant, J. (2018). The great transformation: History for a techno-human future. Routledge.

Bessant, J., Farthing, R., \& Watts, R. (2017). The precarious generation: A political economy of young people. Routledge.

Biesta, G. (2006). Beyond learning: Democratic education for a human future. Paradigm Publishers.

Boateng, Y. (2008). Cognitive capitalism. Polity Press.

Department of Basic Education. (2019). Digital skills framework grade R to 9. Government Printers.

Department of Higher Education and Training (2013). White paper for post-school education and training. Government Printers.

Department of Higher Education and Training (2019). National plan for post-school education and training. Government Printers.

Department of Telecommunications \& Postal Services (2017). Digital skills strategy of South Africa. Government Printers. 
Frey, C. A., \& Osborne, M. A. (2015). Technology at work: The future of innovation and employment. http://www.oxfordmartin.ox.ac.uk/downloads/reports/Citi_GPS_Technology_Work.p df

Gleeson, N. (2018). Introduction. In N. Gleeson. (Ed.), Higher education in the era of the fourth industrial revolution (pp. 1-11). Palgrave Macmillan.

Maton, K. (2014). Knowledge and knowers: Towards a realist sociology of education. Routledge.

Motshekga, A. (2020). Address by the Minister of Basic Education, at the 2020 Basic Education Sector Lekgotla held at Emperors Palace, Kempton Park, Gauteng Province, 15 January 2020.

https://www.education.gov.za/Newsroom/Speeches/tabid/950/ctl/Details/mid/8848/Ite $\mathrm{mID} / 7779 /$ Default.aspx

Nair, P. (2020). Preparing 21st century teachers for Teach Less, Learn More (TLLM) pedagogies. In P. Kumar, M. Keppell, \& C. Lim (Eds.), Preparing 21st century teachers for Teach Less, Learn More (TLLM) pedagogies (pp. 1-9). IGI Global.

National Treasury (South Africa). (2018). Service Delivery Review, 11(3).

Nzimande, B. (2019). Address at the launch of the School for Data Science and Computational Thinking at Stellenbosch University, 29 July. http://www.sun.ac.za/english/data-science-and-computational-thinking

Peck, J., \& Theodore, N. (2016). Fast policy: Experimental statecraft at the thresholds of neoliberalism. University of Minnesota Press.

Penrose, B. (2018). The fourth industrial revolution and higher education. In Gleeson, N. (Ed.). Higher education in the era of the fourth industrial revolution (pp. 207-228). Palgrave Macmillan.

Peters, M., \& Jandric, P. (2019). Education and technological unemployment in the fourth industrial revolution. In G. Redding, A. Drew, \& S. Crump (Eds.), The Oxford handbook of higher education systems and university management (pp. 1-23). Oxford University Press.

Ramaphosa, C. (2020). Acceptance statement on assuming the chair of the African Union for 2020. 33rd session $\mathrm{f}$ the African Union Assembly, February 9, Addis Ababa, Ethiopia. https://au.int/sites/default/files/speeches/38086-sp au_acceptance_statementenglish.pdf 
Rajkumar, R., Lee, I., Sha, L., \& Stankovic, J. (2010, Sept.). Cyber-physical systems: The next computing revolution. In Proceedings of the $47^{\text {th }}$ Design Automation Conference DAC'10 (pp. 731-736).

Schwab, K. (2015). The fourth industrial revolution: What it means and how to respond. https://www.weforum.org/agenda/2016/01/the-fourth-industrial-revolution-what-itmeans-and-how-to-respond/

Statistics South Africa. (2019). 28,000 job losses in the formal sector third quarter of 2019. Department of Statistics. http://www.statssa.gov.za/?p=12842

Sutherland, E. (2020) The fourth industrial revolution - The case of South Africa. Politikon, $47(2), 233-252$.

World Economic Forum. (2016). Future of jobs: Employment, skills and workforce strategy for the fourth industrial revolution. http://www3.weforum.org/docs/WEF_Future_of_Jobs.pdf

Young, M., \& Muller, J. (2010). Three education scenarios for the future: Lessons from the sociology of knowledge. European Journal of Education, 45(1), 11-24. 